\title{
El pensamiento frente a la historia
}

\author{
Andrés Inurreta Acero
}

\author{
Rebeca Maldonado, coord., Tránsito(s) y resistencia(s). \\ Ontologías de la historia. México, unAm, Facultad de Filosofía \\ y Letras/Ítaca, 2017, 350 pp.
}

ué es el ahora? ¿Cómo es que hay algo en este ahora? ¿A dónde ir
desde él? ¿Cómo nos ha sido legado? ¿Podemos incidir en su curso?
¿Cuáles son las fronteras de esa transformación y nuestras potencias
creadoras? ¿Se puede reformular el pasado? ¿Qué posibles caminos se abren en el trayecto de nuestra existencia? ¿Qué decir sobre nosotros y para qué interlocutor? Con estas preguntas, el volumen coordinado por la doctora Rebeca Maldonado replantea el carácter problemático del tiempo, refrescando aquello que, de manera equivocada, se creía necesario que la filosofía debía dejar de lado: la historia. El libro Tránsito(s) y resistencia(s). Ontologías de la historia, sigue los caminos que la ontología recorrió durante el siglo Xx, situándose en la quiebra de las esperanzas, un velo que al caerse mostró el horror de la sofisticada crueldad de la que somos capaces.

Lo que se descubre es una ontología que se pregunta constantemente por el presente. En lugar de desechar, replantea, reformula y busca nuevas rutas, las cuales fundan la divergencia desde el fundamento, promoviendo un pensar nuevo. Así, el proyecto está cargado de urgencia ante las promesas del progreso ordenado que ha traicionado la tranquilidad con la que se movía la humanidad hacia los fines planteados. Frente a la desolación, el pensamiento se levanta para hacer patente que aún podemos pensar. De tal manera, Tránsito(s) y resistencia(s). Ontologías de la historia se convierte en un abanico que da testimonio de ello. Los investigadores que han tomado parte en su realización hacen evidente que la filosofía no se detuvo; que ésta, en medio de las convulsiones de la historia, nos es necesaria. Así, pensadores como Kierkegaard, Nishitani, Kitaro, Heidegger, Ortega y Gasset, Derrida, Deleuze, Foucault, Žižek, Bergson, Weil, Ricoeur, mediante el reordenamiento ontológico del tiempo indican posibilidades históricas que aparecen como un cuadro impresionista que resiste a las lúgubres paredes de los campos de concentración nazis, del Gulag o de Guantánamo. 
Quienes desechan por completo la pregunta por la historia, son aquellos que sólo pueden mirarla desde los ojos puestos en el fin del horizonte. El escepticismo en los grandes relatos, que justificaban el caótico devenir del tiempo, sucede desde la nostalgia por el pasado que se nos muestra como "época de oro", a la que la mayoría acudimos para vestirnos como imitaciones de los fantasmas que miramos con admiración; así también, y más importante e irónico, nostalgia por el futuro como porvenir de la realización de lo que acontece detrás de lo aparente. Con la negación de la historia se niegan los fines; en esta actitud se esconde el anhelo de dichos fines, pues responde a la metafísica misma que los suponía; se llega a creer que una vez aniquilada la historia, como la piensa la modernidad, no queda nada que decir acerca de ella.

Lo que sale a relucir con las propuestas que desean acabar con la historia, ya sea mandándola al olvido o declarando su cumplimiento, es una metafísica que coloca el acento en la distinción del ser y lo existente, en donde el tiempo y el devenir, ya sea reivindicado o despreciado, es un resultado y no la condición del ser, el cual a su vez es conceptualizado como ente que existe independiente del mundo. Tránsito(s) y resistencia(s). Ontologías de la historia marcará otra vía para comprender la historia disidente de las ontoteologías de la modernidad que en la Ilustración se fue consolidando como la filosofía de la historia en un proceso de secularización del cristianismo.

Teresa Oñate, en el prólogo al libro, nos ofrece el recorrido que la filosofía realiza desde Tomás de Aquino, pasando por Kant, como momento en el que se piensa el ser separado de las cosas; hasta la época inaugurada por Friedrich Nietzsche, denominada por ella, postcristiana, frontera desde la que propone pensar la historia. Oñate ve en la caracterización del ser que Tomás de Aquino presenta, el paso a una realidad dependiente con la que se inaugura el pensamiento histórico cristiano. Tomás de Aquino concibe al ser como existencia, la cual se halla lejos de las esencias; éstas no tienen existencia por sí y llegan a ser cuando Dios se las conceda. Lo que es se separa de lo que sucede, y esto último se entiende como resultado condicionado al movimiento de lo que existe. Lo que existe ya no es el tiempo, ni tampoco las cosas que en él surgen y desaparecen. Todo aquello encuentra su justificación en lo externo e inamovible. Por Dios es que las cosas llegan a ser, la existencia les es otorgada; es uno y por uno, la verdad detrás de las cosas. ¿Acaso Cristo muere de nuevo? El sacrificio del hijo del hombre no sucede nunca más. Al ser bajado de la cruz, ésta no vuelve a levantarse. La circularidad de la historia es un sacrilegio, puesto que el cristiano cree en el evento único del dios encarnado y espera lo no sucedido aún, la parusía. La desgracia humana del ahora encuentra un propósito en lo venidero, en un reino transhistórico de cuerpos reformados en el que el tiempo desaparece. La esperanza cristiana es puesta 
en la negación del ser-espacio-tiempo cuyo encuentro más contundente es la corrupción y la muerte.

Dicho anhelo es heredado a la modernidad, cuyas propuestas también se basarán en una salida del tiempo que adviene en el final de la historia. Kant aparece como el responsable de la legitimación de las pretensiones ilustradas de colocar a la razón como garante de nuestras acciones. Cuando el filósofo de Könisberg pone mayor peso sobre la práctica, el saber teórico, según Oñate, como pensar el ser es abandonado, se resuelve como ciencia determinista. De tal manera que la praxis kantiana se constituye antropocentrismo en favor de la libertad del sujeto; el cual hace parecer el mundo como una colección de objetos que adquieren su propósito en manos del hombre, quien otorga sentido al colocarlos en el espacio y en el tiempo. El responsable del transcurso será el hombre; no cualquiera sino el racional. Entonces, aceleremos ese acontecimiento del final, por el cual la muerte de las generaciones pasadas sea justificada, generaciones incompletas de seres incompletos. El porvenir se levanta sobre sus penas, las cuales garantizan un peldaño más en el progreso de la historia ¿De qué otra manera la imperfección y el mal tendrían sentido si no fuera en el porvenir cada vez más elevado en la razón descubridora de la verdad? Como dan cuenta de la fragilidad que tal empresa supone al depender de nosotros, debemos luchar contra la incivilizada barbarie ajena. Hacia ese futuro debemos ir todos -como en la salvación ecuménica del cristianismo. La modernidad se lanza a la conquista de los otros para hacerlos entrar a la marcha de la historia. O es universal o no es historia. Negación del tiempo. Negación de lo otro. De tal manera, la modernidad no logra superar a Dios como justificación del mundo en el que vivimos, lleno de cambio en donde la carne no soporta el tiempo.

Cuando Nietzsche anuncia la muerte de Dios, muere todo aquello que había sido depositado en sus hombros, a saber, la justificación del sometimiento de lo que acontece, como apariencia, a una realidad que le trasciende, que se esconde detrás, no sólo como lo que realmente es, sino también como causa de que lo aparente se presente. El mundo sensible, que es ahora -interminable, perpetuo-, quedaba subsumido al mundo allende al presente de nuestros sentidos, por lo que la vida pasaba como un espejismo, es decir, un engaño. Lo que muere con Dios no sólo es el fundamento, el sustrato, el sujeto, que unifica, que da sentido y existencia; también las determinaciones y generalizaciones, las cuales sirven de censura de lo distinto. La particularidad se descubre en lo inmediato y en lo diverso como la constancia inconstante, pues lo único que deja ver es la falta de patrones. Con ello, Nietzsche demanda una vuelta a la inmediatez de los sentidos, del tiempo de las sensaciones que es el ahora, al que nos invita a enfrentar como si fuéramos a vivir una y otra vez. El cielo del cristianismo, o el final de la historia, inmóviles ambos, son sustituidos por el eterno retorno. 
Sin embargo, como bien aclara Oñate, siguiendo con ella en el prólogo al libro, la muerte de Dios no debe ser vista como el paso a una nueva época que sucede por la superación de otra; sino como el momento en el que salta ante nosotros la necesidad de pensar de acuerdo con un tiempo ahora postcristiano. De esta manera, no todo ha quedado dicho, más aún, denunciado; y con tal denuncia, puestas las posibilidades en tránsito -ahora si en plural- de la ontología volcada a la historia.

Oñate anuncia el problema ontológico-histórico como el más apremiante de nuestra época, puesto que estamos colocados en ese tránsito: en el pasar a... pasado el desde... Lo que queda en medio es el ahora abierto situado en el entre. El entre, el lugar de tránsito de una época a otra, demanda que continuemos pensando la historia por el simple hecho de que la apertura en la que nos encontramos nos remite forzosamente a preguntarnos: ¿quiénes somos?, ¿dónde estamos?, ¿a dónde vamos? Cuestiones que nos colocan frente al tiempo como testigos que somos de él. Descubrimos un antes que ha muerto, que hoy otorga poco para mantenernos en nosotros; pero que de alguna manera pone palabras en nuestra boca, palabras que no nos pertenecen. Un nuevo hablar se esconde en la neblina del problema que trae consigo el surgir de otro ahora, el cual tiene carácter antagónico, actitud de enfrentamiento que termina en el choque entre el surgir y el persistir.

El choque no sucede como la discusión de dos perspectivas disímiles, opiniones o discursos que se ponen en duda uno a otro, sino como la realidad misma en la que habitamos. El choque es la condición histórica en la que nos encontramos; una línea en la que el cristianismo secular y el postcristianismo se encuentran en pugna. Una advertencia de Oñate; el gran peligro del entre es que las nuevas propuestas, ante el rechazo y la aniquilación, suavicen su arrojo sobre el conservadurismo para mezclarse con él. De tal manera que al perpetuarse en la continuación de viejas formas, se aplace el pensamiento, precisamente, del entre como historia, acontecer y devenir, del espacio-tiempo-ser.

Por tal motivo es necesaria la creatividad para enfrentar dicho tránsito. Sólo desde el atrevimiento de un pensar nuevo, que no cede a lo anterior, es que podemos elevar una alternativa realmente original, colocándonos frente a las dificultades de abandonar el pasado, cuando el mundo era justificado por otro mundo. Quiere decir que ese pensar debe serle propio a lo inmediato, situarse en sus límites y trabajar con ellos para evitar crear un becerro de oro una vez dado a Dios por muerto. Precisamente encontraremos que desde las distintas perspectivas que se plantean en el libro, la creatividad será una propuesta recurrente, concebida de distintas maneras; pero siempre tendiendo hacía la resistencia frente a la rigidez, desde la actualización innovadora como alternativa a la máquina. 
En los artículos que inician el libro se retoman para empezar, Henri Bergson, por María Elena Lisboa en "Tiempo y subjetividad en Henri Bergson”, y Soren Kierkegaard por Elsa Torres en "Poética del instante: eternidad y temporalidad en el pensamiento kierkegaardiano".

En el caso de Bergson, responderá a la noción del tiempo como condición a priori de la razón, al colocarlo como la realidad misma asequible sólo en cuanto se tenga intuición del durante, forma de conceptualizar el momento en el que algo es, entendiendo que algo es siempre en el cambio y el movimiento. Por ende, un tiempo creador que da paso constante a lo nuevo, en la actualización de lo que se presenta necesariamente corpóreo.

Kierkegaard, nos dice Torres, responde a Hegel, para el cual, el tiempo parte de la verdad objetiva como concepción de lo histórico universal; por el contrario, el filósofo danés ve el tiempo como incertidumbre objetiva, colmado de interioridad subjetiva, paradoja y carácter decisivo en el salto cualitativo entre los estadios de la existencia.

Se incluyen en la lista de autores revisados y comentados dos miembros de la escuela de Kioto. Ésta nos aleja del tiempo escatológico del advenimiento del reino de los cielos, el cual nos es abierto por el perdón de Dios, llevándonos de vuelta al momento presente por el cual nos hacemos responsables creativamente. A diferencia del mañana esperanzador, el momento actual es reivindicado como punto de partida constante, por el cual el ahora es siempre un prestar atención a falta de jerarquía respecto de un antes o después.

John C. Maraldo en "La ontología de la historia de Nishida Kitaro" nos da a conocer a su fundador, el cual llevará su trabajo por la ontología de la historia con el mayor objetivo de que nada quede fuera de ella. Consecuentemente, el presente tomará la dimensión completa del tiempo, al liberarse de la visión teleológica, haciendo saltar entidades transhistóricas ilegítimas al instante. La historia se revela como presente absoluto en el cual pasado y futuro son reconfigurados en una constante realidad creativa, en la cual quedamos inmersos como agentes creadores que son transformados al situarnos en lo cotidiano.

Raquel Bouso en "Meontología y temporalidad en el presente de Keiji Nishitani" muestra la recuperación de la tradición en el siglo xx del budismo zen llevada a cabo por Nishitani, mediante el pensamiento en torno al vacío. Éste es presentado como inseparable del tiempo, en tanto que la impermanencia de las cosas se da en él. Si algo deja de ser es por falta de fundamento, y como todo deja de ser, nada tiene fundamento. Las cosas no son, suceden en el tiempo-vacío, que es la base de la que surgen tanto samsara como nirvana. La historia es una contemplación del presente actualizado de dicha base, por la cual superamos el nihilismo y el absurdo.

Es de destacar la extensa investigación dedicada a Tratados de la historia del ser de Martin Heidegger, compendio de trabajos póstumos del filósofo ale- 
mán, que le llevó siete años de revisiones, discusiones, seminarios, al equipo coordinado por Rebeca Maldonado. Como ejemplo de ello "La confrontación Heidegger-Hegel. En torno al problema del tiempo y la pregunta por la historia" presentado por Luis Hernández, tiene por tema central la interpretación que realiza Heidegger de la concepción hegeliana del tiempo, considerándola la expresión máxima del tiempo vulgar, es decir, de aquel que se contempla como producto de objetos en movimiento, que pasan de un estado A a un estado B, siendo el caso de Hegel el salir del espíritu hacia el autoconocimiento. Para proponer una vuelta hacia el ocultamiento, por el cual el ser se dona para pensar la historia, ya no como un cúmulo de saber, sino como el acontecer de lo originario.

En "Poder y sitio. Instante de la pobreza como sitio histórico en Martin Heidegger. Ensayo sobre los textos ontohistóricos" la coordinadora del proyecto, Rebeca Maldonado, pone el acento sobre la concepción heideggeriana de la modernidad como época sustraída a la indigencia, al darse a la conquista de lo ente como un imparable acumular cuya finalidad es lo utilizable, es decir, como maquinación. Ésta pone el tiempo de la modernidad en un constante y continuo acrecentar, carácter del progreso, que es en realidad un siempre así. Contrariamente, la indigencia inaugura el futuro como sitio desde el cual se despliega la decisión.

Mario Alberto Sandoval nos ofrece en "El nihilismo como perspectiva: un análisis ontohistórico" una revisión de lo que Martin Heidegger llama el "pensar del evento" o el "pensar del tránsito" en el que se halla una reconfiguración del problema del nihilismo. El nihilismo es propuesto como elemento de quiebre que abre el tránsito de una historia fundada en el pensamiento ontoteológico de la metafísica occidental a la historia de lo no pensado. A partir de ello, la nada es pensada como posibilidad de una fundación histórica desde el mostrarse del ser en su ocultamiento. De tal manera que el nihilismo no deba ser superado en tanto que implicaría nuevamente el olvido de la sustracción del ser en su permanecer fuera.

Más adelante nos encontramos con "Políticas de la memoria y la palabra en Simone Weil: el totalitarismo y la gracia” de Christian Gómez. Si bien se ha propuesto pensar la historia como una disposición de la existencia, en Weil encontramos un acercamiento que poco puede distinguir entre una propuesta política y una experiencia mística, pues Weil va al encuentro de los otros. La historia es el fluir de la fuerza ciega que busca acrecentar por medio del poder, que llega a concretarse en el totalitarismo al transfigurarse en palabra desvinculada de la realidad, reflejo de las ficcionales relaciones sociales. La fuerza está detrás. La mesura, el límite y la debilidad, como actitudes frente a los otros, rompen la voracidad. Simone Weil apuesta por una relación distinta con el otro, basada en el apoyo, la confianza, la donación. 
Sonia Torres en "Gilles Deleuze: nomadología, historia y devenir" nos muestra la diferencia entre el sedentarismo y el nomadismo como dos formas antagónicas de enfrentar el tiempo. Por un lado, el sedentario crea la historia para enfrascar el tiempo en la linealidad donde cada suceso tiene una causa. La necesidad de lo que acontece permite que las mayorías se legitimen al hacer de la historia una especie de árbol genealógico, modelo causal del antes y el después por el que un grupo demuestra su supuesta fortaleza al paso de los siglos. La minoría queda exenta a tal proceso. El nómada acepta el devenir, se mueve en él, existe dentro de su lógica de lo contingente y lo encarna. La nomadología se sitúa en lo múltiple, contempla el aparecer de lo efímero, la potencia de la metamorfosis. Es una máquina de guerra que apunta un arma de fuego a la mesura, los potentados y la quietud.

También participan en la publicación Sandra Montes, Julio Ramos, Greta Rivara, Virginia López, Ana María Martínez de la Escalera, Bily López, Óscar Barroso, Javier de la Higuera, Pablo Veraza y Emiliano Castro.

En conclusión, podemos decir que Tránsito(s) y resistencia(s). Ontologías de la historia se hace de una polifonía en la que se escuchan distintas voces en un contrapunto armonizado con base en las propuestas ontológicas que piensan el tiempo desde el tiempo. Voces que provienen de distintos lugares (México, Estados Unidos, España) y que traen consigo diversas respuestas. Lo que resulta ser consecuente con el tono de resistencia ante lo totalizante. Se logra con ello ofrecer un amplio panorama de la filosofía del siglo Xx que marca los problemas, lanzando luces de bengala a manera de guía, para que hoy los reencontremos. De forma tal que el libro funciona como iniciación.

Tránsito(s) y resistencia(s). Ontologías de la historia es un libro que llama la atención a que pongamos nuestro pensamiento nuevamente en el transcurso de la existencia, pero desde un planteamiento por el cual el transcurso sea lo existente mismo. El libro deja claro que hacer ontología de la historia, repensar el tiempo, supondrá enfrentar los planteamientos que son presentados como inamovibles, ahistóricos, con la cautela de no repetirlos. De lograr esto, nos haríamos con la oportunidad de dar alternativas a las formas de vida que de ellos se desprenden, trasgredir modelos de aceleración, temor, nostalgia, apatía, desde la filosofía, es la resistencia a la persistencia totalizante. Claro está que dicho pensar no puede ser llevado con la intención de dar definitivas universales, sino propuestas multidireccionales que llamen a una reflexión insustituible. Aquello que nos mueve a querer conquistar al otro para llevarle la salvación; hacerle entrar en el tren de la historia apresurando con ello el curso de la humanidad; devastar la tierra como objeto de dominio está planteado ontológicamente en proyectos temporales, de tal manera que puede ser transformado desde la filosofía. En esto está puesta la confianza de quienes conforman el cuerpo de investigadores al abordar dicho problema desde la 
ontología, que al pensar lo que es cambie lo que sucede. De fondo hay una intención política de reorganizar la vida una vez comprendida la realidad a partir de la ruptura ontológica propuesta; que con ello se logre mostrar un rostro distinto de la humanidad y cuyos alcances viren su sentido transformando la relación con la existencia. 